\title{
Body Memory: The change of Dungan people's Folk Life
}

\author{
Liqun Zhang \\ School of Chinese Language and Literature Beijing Normal University, Beijing, 100875, China \\ College of International Cultural Exchange of Northwest Normal University, Lanzhou, 730070, China \\ zhlqflame@163.com
}

Keywords: Body memory, Physical practice, Folk life, Dungan people.

\begin{abstract}
Folklore is not always static, and the body constantly participates in the adaption in the process of displaying, remembering, and inventing folklore. The body helps folklore individuals adapt to the surrounding environment and seek group identity. The body is not only the target of folk disciplines, but also a distinctive symbol that expresses the value and significance of existence. The effectiveness and adaptability of folk life are manifested in the use and carrying of the body. After migrating from China, Dungan people became a multi-dimensional carrier who has an inherited traditions and new invented traditions in the exotic cultural space. The change of folk life can be found in the process of constructing the expression of its own body.
\end{abstract}

\section{Introduction}

The anthropologist Marcel Mauss puts forward the concept of "techniques of the body", which holds that a person's life is a process of acquiring and interacting with others by training for the various physical techniques recognized by the society. As in physical study of social practice, Mauss believes that some basic aspects of physical behavior, such as walking, standing, waiting, are the result of social practice [1]. Paul Ferdinand Schilder believes that the social attribute of the body determines its response to the reality of contact, the body image must be social, and all aspects of body image are constructed and cultivated through social relations [2].

The body is an important carrier and node of connecting social relationship, power politics, emotion, consciousness and culture. As a result, the individual's body is constantly portraying the memory of the inheritance within the group, practicing the experience of ancestors, completing the identity of the self, but also to build the identity of other groups outside. After the infiltration of time, this physical practice is quietly occurring in everyday life and gradually internalized into a code of group.In turn, it governs the practice of individual body, and slowly rewrites the folk tradition and culture of a group. Dungan people inherits traditions in exotic environment with their body as a group with special history, clings to the roots of culture, to coordinate and integrate with the surrounding social space. They realize the writing and rewriting of the folk life of the group. Whether they remain change or not, it is based on the needs to the adaption to the environment and the survival and continuation of the ethnic group.

Dungan people is currently living in Central Asia Kyrgyzstan, Kazakhstan and Uzbekistan, one of the Muslim people, the total population of more than 100, 000. They are the descendants of Hui people who migrated from the Northwest China in the late Qing Dynasty. For more than 100 years, Dungan people has preserved the customs, language and culture of the Hui nationality in northwest China. They still have a strong accent of Shaanxi and Gansu dialects. Comparing their current folk life with the northwestern region of China, we will find that although the living environment of Dungan people is far from China, the customs and habits are the same. Their life can be regarded as the "living fossil" of Northwest folk custom during the late Qing Dynasty. At the same time, because of the new living environment changes, as well as the influence of Turkic and Slavic cultural surrounding, there has been a great change in the customs of them. The contents of their folk customs 
and changes, and the reasons for the change are worthy of our consideration and research. From the physical point of view, we can see the historical choice of Dungan People's folk life.

\section{Group Identification of body construction}

We can imagine that the first generation of Dungan people's survival is extremely difficult, only those people who must be adaptable and physically strong can reach after a long and arduous journey. They are faced with a completely unfamiliar environment, for an ethnic group, the first need is to seek their own living space and location in the new region. In order to fight for the right to survive, they have to compete with the natives in resources and spaces. They require both strong internal cohesion and flexible mediation to expand the living space of the ethnic groups in the new land. It is a necessary and a wise choice to change the physical and mental state for constantly adapting to the new environment.

Land is the first resource to be acquired. Because of the lack of land, many Dungan people had to rent the land of Kyrgyz people. They bring their grandparents ' agricultural physical experience into a foreign country as the basis of survival. They have the own farming experience and culture symbols on their homes and have a personal experience and feelings for special time and space. Land, homeland and hometown are an extension of the body in specific time and space at a deeper level [3]. The tools used by Dungan people in a foreign agricultural production are traditional Chinese rafts, shovel, bars, wooden fork, roller, etc. These are the special tools for farmers in northwest China to cultivate land, weed and pile grass. But then the Russian iron ploughs squeezed out their tools, and when they dig the soil, the Dungan people almost no longer use the bars. In the early 20th century, the Dungan people also learned to use the Yuechu(a kind of hoe) from the local Uzbeks to sort out the sowing areas for digging and leveling the fields [4]. Dungan people carried several generations of labor experience when living in China, each farm tool may be customized with their own hands and body and the tools are adapted to the body. However, as the environment changes and the land changes, people have to adjust their physical state to adapt to the tools. Dungan people change their traditional body skills and adapt quickly under the pressure of harsh living conditions. They not only carry the experience of China's agricultural production, but also change the skills of the tools, turning the barren land into a treasure land for the production of food and vegetables, solving the problem of survival.

The survival problem also includes maintaining a good communion relationship with other ethnic groups around. The best way is to learn new ways of interpersonal communication, etiquette, action, behavior, etc. The hand played an important role in acting as a carrier of meaning for the outward construction of identity. First of all, it is reflected in the changes in the etiquette of Dungan people. Judging from the current handshake ceremony of Dungan men, it is not the tradition of the Hui people in Northwest China. The women adapt "face-to-face ritual"that embrace each other which is not the same as the traditional etiquette of the Hui people. This kind of etiquette is the same as that of the current Kyrgyz and Kazakh ethnic groups in Central Asia. This kind of physical behavior is Paul Connerton's "Incorporating". Everyone in the group is involved in this specific activity in order to convey the message [5]. The acquisition and imitation of this handshake posture, passed down from generation to generation as a "correct" meeting etiquette, without deliberate learning, subtly engraved in the body's memory. When asked some Dungan young people why shake hands like this, the answer is "I do not know" or "It is just like this since childhood, no reason".

Thus the new body is "invented". The body has not only completed the inheritance of knowledge and cultural patterns as a symbol of rewriting history, but also completed the folk rewriting in the process of socialization. Just as Foucault believes that the body can be trained and marked, showing certain rituals and emitting certain signals [6]. Through the body, its physiological experience is regulated by the social cognitive category, thus maintaining a specific view of society. The continuous exchange of meaning between the social and physical body and the two experiences of each other consolidates their respective categories. In view of the result of this interaction, the body 
itself becomes a highly restricted expression medium [7]. The body is seeking "understanding" by shaking hands - the external body attribute, seeking to be the expression of the "internal" personality of other ethnic groups around. The body can be the expression of multiculturalism, the expression of the expansion of the living space and the construction of self-discourse, as well as the inheritance of tradition and the expression of exclusion in foreign space.

\section{Emotional maintenance of body memory}

In terms of food culture, Dungan women still retain the produced method in which the Hui people's diets such as Mianpianzi (a kind of home-made noodle-pieces), home-made noodles, Sanzi and Mahua (two kinds of twist pasta), the action of making is still unchanged, maintaining the "boundary" of the group in the body, distinguish the surrounding cultural context with body language. These emotional way, feelings, behaviors and norms are formed in their own festivals, rituals and daily life. They are used to being natural in the eyes and ears, and become an unforgettable knowledge and cultural pattern. Anthony Giddens points out that the body becomes part of modern reflection, and that physical embedding is the basic way to maintain a consistent sense of self identity in the interaction of everyday life, there is a special connection between body and self-identity, the body is directly involved in the principle of constructing oneself in a post-traditional environment of a high degree of modernity [8]. It is this unchanging body consciousness that strengthens the ethnic consciousness and individual consciousness of Dungan people. It is the consciousness that produces a strong cohesive force that is why this nation survives in a difficult situation and retains its present characteristics with its distinctive features.

In addition, we can also see the body's inheritance of folklore from wedding dress of Dungan women. Until today, when the Dungan people get married, the bride wears a cheongsam, a cheongsam with double forks, embroidered shoes and cloth socks embroidered with peony flowers. This was the Manchu costume at the end of the Qing Dynasty. They chose the Manchu cheongsam as their traditional national costume, and insisted on showing it at the wedding and all ethnic celebrations. This costume is Manchu in China and unique to Dungan in Central Asia, it is one of the cultural characteristics of Dungan people [9]. The author believes that the reason why cheongsam was preserved was because of the auspicious patterns on cheongsam, expressing the pursuit and yearning for a better life, which no group or individual can refuse. Secondly, most cheongsams are luxuriously embroidered, the auspicious symbols of peony or phoenix are loaded and the bright colors, the high-end decorations creat a strong visual impact,which can also express special meaning aestheticly.

When the body builds community identity inward, it often conveys the characteristics and the most representative parts of the ethnic culture, and filters out the homogenized information. The body is the externalization of its own aesthetic concept, it is a socialized performance. According to Goffman's performance theory, this kind of physical performance can be modified according to social scenes, expressing the value of the group or individual as needed. Through performance, in the process of self-labeling and dramatization, the Dungan group "elegantly wrapped themselves up in the concept of 'we' with the inseparable role of the cloak" in the exotic place [10]. These symbols with impact visual and memory have been fixed and become the symbol of the Dungan group, becoming a clear and profound image in the eyes of the "others". Through the body's inheritance of folklore, it not only expresses the cultural symbols of "my group", but also constructs clear boundaries and maintains the identity within "my group".

\section{Conclusion}

Each group automatically appoints the body to the values and categories they need most [11]. In the process of migration and integration into the new environment, Dungan people created and strengthened various self-identity/identification symbols in migration and adaptation to social 
context changes. These symbols also show the vitality and effectiveness of a folklore in its inheritance and evolution. As far as Dungan people are concerned, they are a unique cohesive society. They need to seek recognition from the outside and maintain their emotions inward. It is precisely in the continuous integration and compromise that they have formed today's culture. It can be seen that the body is not only the object of folk discipline and inheritance, but also the thing-in-itself of changing folk customs. While folk life is shaping, producing, and reproducing a body that conforms to a specific cultural tradition, the body is actively changing the folklore. Balance between physical and social environment, the body in the active adaptation, change, acceptance of the process of "logical, reasonable, identity" coordination.

The power of survival and the construction of identity are important reasons for determining the change of folk life. It is a factor that cannot be ignored in the historical process of the formation and development of Dungan people's ethnic consciousness. No matter change or not, it is the meaning and value of seeking existence through the body.

\section{References}

[1] Marcel Mauss, Sociology And Anthropology, Shanghai Translation Publishing House, pp. 397-404, 2014.

[2] Wang Min'an, Cheng Yongguo, Post-Body: Culture, Power and Life politics, Jilin Publishing House,pp.28,2011.

[3] Gan Zheng, The change and reconstruction of traditional festival folk custom-based on the perspective of body folklore, Social Scientists, vol.4, pp. 154, 2016.

[4] Сушанло M.H., The history and culture of Dungan people in Central Asia, Ningxia People's Publishing House, pp. 85-86, 1996.

[5] Paul Connerton, How Society Remember, Shanghai Publishing House, pp. 91, 2000.

[6] Michel Foucault, Discipline and Punishment, Sanlian Publishing House, pp. 27, 1999.

[7] Peng Mu, Folklore and body--the body Research of American folklore, Folklore Studies, vol.3, pp. 24, 2012.

[8] Anthony Giddens, Modernity And Self-Identity, Sanlian Publishing House, pp. 111-115, 1998.

[9] Ding Hong, Dungan Culture Research, Central University for Nationalities Press, pp. 279, 1999.

[10]Erving Goffman, The Presentation of Self in Everyday Life, Peking University Press, pp. 46, 2008.

[11]Paul Connerton, How Society Remember, Shanghai Publishing House, pp. 125, 2000. 